\title{
Blended Learning Approach in UAE Higher Education: A Selected Annotated Bibliography
}

\author{
Olga Samsonova
}

Higher Colleges of Technology, Abu Dhabi, UAE

osamsonova@hct.ac.ae

\section{ABSTRACT}

In the present time, the required value of education can be achieved only by changing the parameters related to technology use and transforming a classroom into a student-centered that meets different students' needs and learning styles. The blended learning (BL) approach to learning has been the object of various studies in the last two decades as a way to achieve the required results. Many higher educational institutes started to prefer BL over traditional teaching, and the UAE universities are not exceptions. There has been an increased recognition of the fact that more attention needs to be paid to this area. Hence, this selected annotated bibliography aimed to find out and describe the primary outcomes of the BL approach research in this country. Emergent themes from the UAE studies include 1) students' and instructors' technology readiness and their attitudes towards E-learning; 2) students' and instructors' views and experiences with BL approach; 3) BL tools and technologies (mobile learning and social-networking sites); 4) BL resources (Blackboard Learn, video content, online discussions, and Google Docs); 5) impact of BL. Twenty studies have been used for this review. The primary audience for this annotated bibliography is BL researchers.

Keywords: blended learning approach, students' attitudes technology, e-learning, technology readiness, mobile learning, social networking sites, learning management systems, blackboard learn, video content, online discussions, Google docs

Cite this article as: Samsonova, O. (2020). Blended Learning Approach in UAE Higher Education: A Selected Annotated Bibliography. International Journal of Higher Education Pedagogies, 1(1), 13-22. https://doi.org/10.33422/ijhep.v1i1.14

\section{Introduction}

The central location made the United Arab Emirates (UAE) an economic and educational hub in the Middle East, and higher education is a primary contributor to the country's economy (Jose \& Chacko, 2017). Thus, it is significant to educate its residents with high-quality standards using novel and suitable methodologies (Jose \& Chacko, 2017). The UAE shifted from traditional to virtual classrooms and was named the "most-advanced E-learning country in the Arab world "(Taha, 2007, p. 353). In the county's vision for 2021, the UAE government promised to build education around research, innovation, technology, and science (Alkaabi, Albion, \& Redmond, 2017) and called instructors to implement learning technology, independent learning, and collaboration into the learning process to prepare students for "a technological workplace" (Kemp, 2013, p.2). All of the governments within the Emirates have established authorities to ensure that the quality of education would be on the highest standards, and higher education in the UAE will become more competitive by raising educational standards and diffusing technology into the educational process (Alsharari, 2018).

UAE universities adapted e-learning technology to drive students into independent learners (Randeree, 2008). In 2012, the UAE Ministry of Education equipped three federal institutions with iPads for the 2012-2013 academic year and encouraged these institutions to start mobile 
education "disrupting" traditional teaching and learning; new modules and activities were designed to support students learning (Gitsaki et al., 2013). LMS systems and Blackboard were embedded in the delivery of the courses (Alkaabi, Albion, \& Redmond, 2017).

Since 1990, the BL approach has been considered a significant part of higher education (Smith \& Hill, 2019). This methodology is known as a student-centered approach where students are exposed to finding information, using critical thinking skills, and being active participants (Randeree, 2008). Based on current research, challenges that BL instructors experience are 1) time preparation increasing; 2) not enough "technical and pedagogical skills"; 3 ) "students' responsiveness and discipline" (Sam \& Soong, 2019, p.5).

Some authors argued that it could be problematic for Arab students to adapt to the BL environment because of the nature of the activities as self-directed; plus, there is a "high score of cultural dimensions of UAE" (Kemp, 2013, p.3). The UAE learners' beliefs and preferences depend on their culture, and Western frameworks for E-learning are not useful for Arab learners due to cultural context (Hiasat, 2018; Kemp, 2013). There are barriers concerning BL implementations in the UAE and not enough research on students' and teachers' attitudes towards BL and their experience with BL (Moussa-Inaty, 2017). This selected annotated bibliography tries to cover the gap since this problem has received limited attention in the literature. It focuses on research outcomes from the UAE studies describing the central BL notions.

Keywords searched included blended learning approach in the UAE; higher education in the UAE; UAE students' attitudes technology; UAE E-learning; UAE technology readiness; UAE mobile learning; UAE social networking sites; learning management systems in the UAE; Blackboard Learn usage in the UAE; video content in the UAE; online discussions in the UAE; UAE Google docs. The results were limited to peer-reviewed articles published within the last six years. The following database was used for the search: Google Scholar; Education Database (ProQuest); Education Source (EBSCO); ERIC (EBSCO); Explora Educator's Edition (EBSCO).

\section{Annotated Bibliography}

\subsection{Students' attitudes toward technology and E-learning}

Andrew, M., Taylorson, J., Langille, D. J., Grange, A., \& Williams, N. (2018). Student attitudes towards technology and their preferences for learning tools/devices at two universities in the UAE. Journal of Information Technology Education: Research. Retrieved from: https://eric.ed.gov/?id=EJ1191028

This mixed-method study aimed to find students' attitudes towards technology, their favorite learning tool or device, their preferences among books and technology tools for the learning process, and see if there any difference in opinions between two UAE universities and two programs. 1102 Arabic undergraduate students participated in this research answering survey questions, and 9 of them joined three focus-group semi-structured interviews. Study participants at both universities agreed that technology is beneficial in the classroom, and 70.3 $\%$ of them stated that technology improves learning. However, paper and books were chosen as preferred learning tools at both universities.

Laptops were the other preferred learning tool due to easy to use fact. Tablets and phones were less favored. Foundation Studies students had more positive attitudes toward technology due to language apps' availability, while General Studies students with STEM courses that contain hands-on activities less likely used technology for learning and prefer books and paper to assist them in their education. 
In conclusion, the authors mentioned some study limitations. Study participants had different course instructors; some of them incorporated the BL approach, and some of them did not, that could impact the technology use level. Besides, study participants were surveyed about the use of technology while being in the classroom. The researchers recommended another study about the use of technology for learning while being outside of the classroom.

Toufaily, E., Zalan, T., \& Lee, D. (2018). What do learners' value in online education? An emerging market perspective. E-Journal of Business Education and Scholarship of Teaching, 12(2), 24-39. Retrieved from: https://search-proquest-com.ezproxy.hct.ac.ae/docview/ 2125613880 ?accountid $=1215$

This qualitative research study was conducted within higher education institutions in the MENA region. The participants belonged to 12 different nationalities: 18 undergraduate and postgraduate students enrolled in hybrid or online programs and 12 undergraduate and graduate students enrolled in face-to-face programs. Conducting semi-structured interviews, the authors aimed to explore students' perspectives-perceived values on e-learning before, during, and after their experience with e-learning.

Describing results, the authors pointed out that before the e-learning stage, the functional value was associated with flexibility and convenience. The conditional value was related to the lack of specific courses and programs and poor credibility of some diplomas. The epistemic value was linked to the educational experience novelty, and the social value was related to cultural and family preconceptions.

During e-learning, the perceptions of values have changed. The functional value was associated with the role of the instructor, extremely positive experience with technology and different social media platforms as YouTube and LinkedIn, and satisfaction with the online curriculum. The belonging value was related to tools of real-time communications with the instructors and classmates, using social networking. Finally, the emotional value was linked to students' fun and enjoyment using social networking for interactions and sharing information.

After the e-learning experience, personal values were satisfaction and self-actualization. Functional values were academic achievement, career advancement, and employment opportunities. Epistemic values determined were new knowledge and novelty.

Tubaishat, A., \& Lansari, A. (2011). Are students ready to adopt e-learning? A preliminary ereadiness study of a university in the Gulf Region. International Journal of Information and Communication Technology Research, 1(5). Retrieved from: https://pdfs.semanticscholar.org/ e9b5/ e5d54f1efdf918a4efa95beb45a6b0116d13.pdf

This survey study was conducted with 67 UAE students taking the BL course. The questioner focused on students' e-learning readiness, such as Internet usage, their perceptions of e-learning and their computer skills, infrastructure, confidence development, and their preferred mode of communication. The survey analysis indicated that all students' own computers, and $99 \%$ of them have an Internet connection at home. Based on the survey results, 93\% of students specified that e-learning enhanced their technical skills, and they became independent learners with online materials. $85 \%$ of the responders stated that e-learning improved their performance. Overall, the majority of the students $(78 \%)$ mentioned that e-learning positively contributed to their learning experience, and they were ready to take any BL course in the future. However, $78 \%$ of male students and $63 \%$ of female students said that they prefer face-to-face communications.

\subsection{Instructors' attitudes and technology readiness}

El Alfy, S., Gómez, J. M., \& Ivanov, D. (2017). Exploring instructors' technology readiness, attitudes, and behavioral intentions towards e-learning technologies in Egypt and the United 
Arab Emirates. Education and Information Technologies, 22(5), 2605-2627. doi:10.1007/s10639-016-9562-1

While collecting data at two private universities in the UAE and Egypt, this research explored instructors' human interactions, technology readiness, behavior, and attitude towards elearning. The research sample contained 31 responders that answered a two-part questioner that was analyzed with the Mann-Whitney U non-parametric test. The results indicated that there is no significant difference between technological readiness, behavioral intentions, and attitudes of Egypt and UAE instructors, and they displayed a moderate level of technology readiness with only a $2 \%$ mean difference from Egypt. Though the human interaction preference is relatively high in both countries which share similar cultural values, according to the authors' suggestions, it can affect instructors' behavior intentions towards e-learning. Preference to face-to-face interactions was slightly higher in Egypt, and it was explained by the fact that in the UAE, most of the instructors are expats committed to using e-learning as institutional requirements regardless of their preferences. To raise the level of instructors' innovativeness and technology readiness, the authors suggested educational training as part of their certification and professional development.

\subsection{BL approach: views and experiences}

Almansoori, S., \& Akre, V. L. (2016). Roadmap for enhancing efficiency and effectiveness of Blended E-learning in Higher Education: A UAE case study. International Journal of Education and Information Technologies, 10, 176-185. Retrieved from: https://pdfs.semanticscholar.org/fd31/df927d08f8edc95f8b5acf2a5240c74c21f0.pdf

The authors conducted this case study in the UAE Higher Educational Institute with 17 graduate students enrolled in a blended e-learning course that incorporated Edmodo and Zoom technologies and synchronous and asynchronous methods along with the teacher of this course. The goal of this research was to propose and validate a roadmap of successful blended elearning. The primary investigation was conducted with both qualitative and quantitative methods by surveying 45 participants and interviewing four experts. As a result, a roadmap for blended e-learning was proposed based on the following factors: characteristics and role of the students (including motivation to learn, technical and communication skills, cognitive presence and involvement), characteristics and role of the teacher (including teaching style, motivation to teach, experience, and level of explanation), social aspects (level of ethics and socialization), and course design (including course content and materials, rules, and levels of asynchronization and synchronization). Responses that came from the case study participants proved the effectiveness of a teacher's role and characteristics of the students. The course design was a weakness of the anticipated roadmap. The authors suggested to use shared materials and create specific course guidelines with video tutorials and screenshots.

Hiasat, L. (2018). Blended and experiential learning for Emiratis in tertiary education. Journal of Asia TEFL, 15(3), 874. doi:10.18823/asiatefl.2018.15.3.24.874

This single case study was devoted to the social processes of learning and teaching that happened in a BL environment in one program at a federal UAE tertiary institution. The data was collected by conducting one-to-one interviews with 11 faculty members, focus group interviews with 36 male students, and collecting relevant documents such as faculty reflections, syllabi, assessment strategies, and the Handbook for Higher Education Teaching and analyzing with NVivo 11 software. The research found that students gave their preferences to independent work and being accountable for it rather than working in groups. Due to cultural aspects, students experienced their education in connections with other events that happened in their lives and valued universal communications and honor. The majority of the students and 
faculty responded positively to experiential learning and founded it very suitable to the second language and visual learners. The flexible BL course structure was preferable in this case study, while the rotation course model was considered as problematic and did not meet the students' needs. The students pointed interaction levels and faculty personalities as main elements of the BL environment in addition to faculties' videos and introductions to the e-books that the students did not like to read. Based on the study results, the author made the following recommendations: 1) avoid tribal issues; instructors must be careful assigning group work and give students flexibilities to join these groups; 2) create the BL environment according to students personal lives; 3 ) use local examples of creating instructional material; 4) spend time on creating joyful BL environment and trust with students.

Kemp, L. J. (2013). Introducing blended learning: An experience of uncertainty for students in the United Arab Emirates. Research in Learning Technology, 21. doi: 10.1016/j.lcsi.2015.07.004

The focus of this mixed-method research was to analyze the cultural dimensions of Uncertainty Avoidance in the introduction of the BL approach. Forty undergraduate students at a UAE university representing 80 nationalities, with $78 \%$ of them being from the Middle East, completed surveys prompted with student narratives about their experiences with BL classrooms supported by LMS and Blackboard. The themes emerged discovered implications for pedagogical changes: 1) instructors have to consider cultural background adapting the BL approach; 2) students require more clearly written and verbal teachers' directions; 3) diagnostic (why answers are wrong) and prescriptive (how the answers might be improved) feedbacks would give BL classes more structure; 4) instructor have to guide students over online material and facilitate online discussions; 5) links to library sources have to be embedded in LMS; 6) a research workshop must be introduced; 7) changing the exam format from written to electronic must be progressive. In conclusion, the author stated that the uncertainty with BL happened when higher quality research methods were introduced to the class, the course structure was lucking details, and when group work was required membership. The study limitation was the fact that their instructor-survey creator made data collection.

Moussa-Inaty, J. (2017). Student experiences of a blended learning environment. International Journal of Learning, Teaching, and Educational Research, 16(9). doi:10.26803/ijlter.16.9.5

This qualitative research elaborated 72 undergraduate female Emirati students' online reflecting journals on Blackboard to examine their feelings toward the BL approach used for an education class offered in English. The participants were native Arabic speakers from different majors, and their mean age was 20.5 years. $43.5 \%$ of them preferred face-to-face learning modules compared to $37 \%$ who preferred BL. Expressing negative or positive feelings, the participants made references to the instructors or the course content. Some participants expressed that BL was very flexible and made them more accountable and independent, while others viewed it as challenges.

Tamim, R. M. (2018). Blended learning for learner empowerment: Voices from the Middle East. Journal of Research on Technology in Education, 50(1), 70-83. Retrieved from: https://eric.ed.gov/?id=EJ1169530

This qualitative research aimed to investigate university students' perspectives of the BL approach in Dubai within their cultural context, which is known as quite conservative. 21 (3 male and 18 female) graduate students-working professionals from different programs were interviewed over the phone or in-person. Most research participants recognized themselves with high technical skills, but the university was their first opportunity to be engaged with BL; though, their new experience improved their self-confidence. Self-regulation and a learner- 
centered model were named as the challenges, mainly at the beginning of the study, but faceto-face sessions worked as support for the students. The author mentioned flexibility provided by technology, higher-order skills enhancement, social interactions with colleagues and instructors, and an online learning platform that minimized participants' feelings of isolation as the strengths. However, technical problems and faculty profiles with the variety presented content, online presence, and teaching styles were called BL weaknesses. Video option was founded as a cultural issue. The authors concluded that BL works as a support for female students to overcome social, geographical, and professional boundaries.

Shantakumari, N., \& Sajith, P. (2015). Blended learning: The student viewpoint. Annals of Medical and Health Sciences Research, 5(5), 323-328. doi:10.4103/2141-9248.165248

Researchers used a cross-sectional study design to examine 75 UAE university medical students' perceptions of BL courses. The Kruskal-Wallis test and Mann-Whitney U-test were used for data analysis. The student survey results showed that: 1) offering a variety of delivery methods, the BL approach was perceived as more effective and less stressful in comparison to face-to-face courses; 2) students improved their communications with classmates and teachers; 3 ) easy to follow course content improved students learning; 4) Moodle learning platform was perceived as user-friendly, and 5) faculty and student technology training and support were called as a critical component of the BL approach. The authors derived that survey results showed no correlation between students' perceptions and their age and gender; however, there were significant differences in opinions on the course enrollment (with the difference in the course duration and the number of online components).

\subsection{BL tools and technologies}

\subsubsection{Mobile learning}

Al-Emran, M., \& Shaalan, K. F. (2015). Attitudes towards the use of mobile learning: A case study from the Gulf Region. International Journal of Interactive Mobile Technologies, 9(3), 75-78. doi:10.3991/ijim.v9i3.4596

This survey study was conducted in the UAE and Oman with a goal to investigate students' and faculty's attitudes towards M-learning in terms of country and gender differences. 225 Oman students, 158 UAE students, 24 Oman teachers, and 30 UAE teachers were surveyed by two types of questionnaires-students' and faculty surveys. An independent T-test was used to examine significant differences. The study results indicated that UAE students showed a more positive attitude towards M-learning compared to Oman students, and there were no differences among faculty of both countries. Also, there were no significant differences amongst students' and faculty's attitudes in terms of gender. $99 \%$ of the students-research participants had mobile devices. In conclusion, the authors suggested policymakers use their study results to make suitable decisions on M-learning usage in the Arab Gulf region.

Halaweh, M. (2017). Using mobile technology in the classroom: A reflection based on teaching experience in UAE. TechTrends, 61(3), 218-222. doi: http://dx.doi.org.ezproxy.hct.ac.ae /10.1007/s11528-017-0184-2

The reflection research method based on personal experience was used to analyze university students' behaviors using smartphones such as iPhone, Samsung, and BlackBerry in Dubai, UAE. The author was using observations and reflections and found two critical issues related to the use of smartphones in the classroom: 1) ways of using phones and policies regulating this usage and 2) technical and ethical concerns associated with phone usage. The research finding pointed the following possible ways of classroom phone usage: a) search and share information; b) use spreadsheets and calculator; c) reading key points of presentation; d) open 
PowerPoints; e) answer instructor questions, or f) evaluate and use specific course-related websites. However, the author stressed the importance of announcing the policies regulating phone usage. The social or ethical issues related to the picture taking during class time may arise since Arab Muslim girls might feel uncomfortable in addition to some social differences and problems related to the type and price of the phone used in the classroom. Perhaps, technical issues related to battery life or WiFi connections might make a class disruption. In conclusion, the author suggested university policymakers formulate regulations for mobile phone usage in the classrooms.

\subsubsection{Social networking sites}

Alzouebi, K., \& Isakovic, A. A. (2014). Exploring the learner perspective of social media in higher education in the United Arab Emirates. Global Education Journal, 2, 13-31. Retrieved from: http://search.ebscohost.com.ezproxy.hct.ac.ae/login.aspx?direct=true\&db=eue \&AN= 99240196\&site=ehost-live

The authors surveyed 731 UAE higher education students exploring their perspectives on the usefulness of social media resources in the BL/online environment using a 5-point Likert Scale. Out of 71 respondents who completed $100 \%$ of the survey questions, more than $60 \%$ were graduate students; $60.6 \%$ were females, and $39.4 \%$ were males. Facebook, Twitter, WhatsApp, and iPhone technology were discussed in the survey, and iPhone technologies were rated as the highest use, while Facebook was ranked as the lowest. Most of the participants agreed that social media tools are more valued for social interactions; Twitter and WhatsApp were emphasized, especially for communication with the instructor. The authors concluded their study with the findings that there is no significant influence of demographic aspects on students' perceptions of social media usage in the classrooms.

Alkaabi, S. A., Albion, P., \& Redmond, P. (2017). Social network misuse in the classroom and its impact on male student motivation in UAE tertiary education. IAFOR Journal of Education, 5(SI), 115-131.doi:10.22492/ije.5si.05

This qualitative study was conducted in UAE tertiary institutions and aimed to investigate 83 male students' experiences in public higher education. Thirteen focus groups with English as their second language were conducted within universities adapting the BL approach in their curriculum. The addiction to social networks and their impact on students' motivation was one of the main discussed issues. The study results were divided according to social networking use and its effects. Facebook, Twitter, WhatsApp, YouTube, Instagram, BlackBerry Messenger, WeChat, Skype, Tumblr, Keek, and social games were cited as main networks used for social (entertainment and interactions) and academic (learning and cheating) purposes within the classroom. The participants mentioned that they accessed these social networks due to addiction, boredom, or to annoy the teacher. Students' views included positive impacts of social networking related to accessing news, learning new words, or watching funny videos and adverse effects such as addiction, lower motivation, social isolation, weak academic outcomes, and inadequate time organization. In conclusion, the authors proposed recommendations for better social networking utilization: 1) use of "a three-point remedy" that starts from implementing academic integrity policies, blocking social networks during exams, and then report and punish cheaters and 2) use social networks as educational tools.

\subsection{BL resources}

\subsubsection{Blackboard Learn}


Baburajan, P. K., Noushad, S., \& Shaikh, A. A. (2019). Users' perceptions and experience in Blackboard learn functionalities. In 2019 Advances in Science and Engineering Technology International Conferences (ASET) (pp. 1-6). IEEE. doi:10.1109/ICASET.2019.8714473

This research focused on the Higher Colleges of Technology (HCT) teachers' and students' experiences and perceptions of Blackboard Learn (BBL) functionalities. Surveying 127 Business and Engineering students and 41 faculty members, the authors gathered the research data. The majority of the research participants reported being excellent or good users of BBL with support from the Ed-tech division that offers a wide range of professional development courses. $80.5 \%$ of faculty and $35 \%$ of students stated that they prefer a mix of BBL and traditional instructions: $57.8 \%$ of business major and $40 \%$ of engineering major students preferred this combination. The conventional model provided students with face -to face support, and engineering students required much more help with their courses, while BBL mode offered students from different locations and, with varying family situations, the opportunity to assess their classwork 24/7 from any suitable location. Findings indicated that the "e-textbook" and "Discussion board" functions were underused by both majors' students and made the conclusion that the BL approach was, in general, favored by student and teacher research participants.

Daouk, L., \& Aldalaien, M. (2019). The usage of E-learning instructional technologies in higher education institutions in the United Arab Emirates (UAE). Turkish Online Journal of Educational Technology-TOJET, 18(3), 97-109. Retrieved from: https://search-proquestcom.ezproxy.hct.ac.ae/docview/2275071751?accountid=1215

The authors conducted a qualitative auto-ethnographic study that aimed to find out positive factors that affect the Blackboard Learn adoption among the UAE higher education faculty. The research data was collected from the personal researcher reflections and their interactions with colleagues coded in NVivo. It was confirmed by the study results that aspects of perceived innovations such as 1) resource sharing (accessible and easy); 2) communication (emails with stored students and faculty emails, discussions, announcements); 3) compatibility (with Excel downloading and uploading, MS Word, and PowerPoint, and with exam authoring system Respondus 4.00); and 4) usability of tools with a high level of complexity measure the success of e-learning system diffusion. However, a low level of trialability and increased complexity were deliberated as negative sides that affect the adoption rate. Emails, interpersonal communications, and training were named as faculty communication channels, and the authors stressed the fact that these channels are required for improvement, and the number of channels has to increase. Social system and time were confirmed as essential variables with the support from early adopters, opinion leaders, and change agents for e-learning system diffusion.

\subsubsection{Video content}

Ahmed, W. K., \& Marzouqi, A. H. A. (2015). Using blended learning for self-learning. International Journal of Technology Enhanced Learning, 7(2), 91-98. doi:10.1504/IJTEL.2015.072025

This research discussed the use of a BL approach for UAE undergraduate engineering students' skills enhancing. During the study, the lectures were recorded and delivered using iPad applications and YouTube video software, and students' feedback was used for the data analysis. Based on student survey results and instructors' experience, Educreations and Camatasia Apps were found most useful in terms of voice recording and main features in the Apple store. $69 \%$ of the students preferred to study through videos, and $87.5 \%$ strongly agreed with having videos of the tutorial problems. $75 \%$ of the students preferred their course instructors to make the tutorial videos. Besides, about $63 \%$ of students stated that they would 
add extra material based on their interests. Findings indicated that the iPad Apps features for interactivity are limited, and the use of Apple-iBook Author with embedded widgets on laptops or Mac desktops would enhance the lesson materials.

\subsubsection{Online discussions}

Awofeso, N., Hassan, M., \& Hamidi, S. (2016). Individual and collaborative technologymediated learning using question \& answer online discussion forums-perceptions of Public Health learners in Dubai, UAE. Open Learning: The Journal of Open, Distance, and eLearning, 31(1), 54-63. doi:10.1080/02680513.2015.1120662

This case study focused on the usefulness of discussion forums focusing on perceptions of 25 Master and 8 Bachelor UAE university students. Five different discussions were posted on the Moodle platform and were incorporated into the assessment rubrics and learning activities of the courses. $67 \%$ of the Master students and $80 \%$ of Bachelor students preferred discussions and group work rather than individual tasks. However, several Master students complained about hiding other posts before submitting their posts, while Bachelor students liked that fact. Both Bachelor and Master students underlined that instructors gave comprehensive feedbacks to everybody's responses that facilitated individual and collaborative learning.

\subsubsection{Google Docs}

Ishtaiwa, F. F., \& Aburezeq, I. M. (2015). The impact of Google Docs on student collaboration: A UAE case study. Learning, Culture and Social Interaction, 7, 8596.doi:10.1016/j.lcsi.2015.07.004

Using a mixed-methods approach, the authors aimed to discover the collaboration impact of Google Docs and limiting collaboration factors in the UAE. Semi-structured interviews with 14 undergraduate students from different specializations and a questioner completed by 142 registered students were the study instruments. The data was analyzed by employing SPSS. The research results showed that students held favorable views towards and for Google Docs promote: 1) instructor-student interactions; 2) instructional collaboration; 3) student collaboration. The significant challenges that are limiting Google Docs usage were cited as a lack of technological and teamwork skills, plus, preference for other tools and extra time required for Google Docs use. The research authors provided some recommendations to increase the use of Google Docs, such as creating online activities that support and motivate students' collaboration, allow them to comment on each other's work, and teach them this tool's features while monitoring students' progress.

\subsection{BL approach: impact}

Aldalalah, O. M. A., Shatat, F., \& Ababneh, Z. W. (2019). The impact of blended learning on the development of cognitive and metacognitive thinking skills in the mathematics of the (ECT) students. Journal of Institutional Research, South East Asia, 17(1). Retrieved from http://search.ebscohost.com.ezproxy.hct.ac.ae/login.aspx?direct=true\&db=eue \&AN=1370835 $54 \&$ site $=$ ehost-live

The purpose of this mixed-methods research study was to measure the impact of BL on the development of metacognitive and cognitive thinking skills of UAE college students. Thirtyone faculty members and 95 undergraduate students enrolled in the Math course (40 of them were assigned to a traditional group while 55 students were placed in the BL group). The Math achievement test with 20 questions was used to recognize how compelling the BL course was. The study found that BL supported students to perform better in metacognitive and cognitive thinking skills, providing enhancement through instructional software. Learners can browse 
the instructional content at any continent time for them. BL assessments diminished test frustration and anxiety. The authors suggested BL integration into all Math courses since online communications and flipped learning support students in solving any acquired problem.

\section{References}

Alkaabi, S. A., Albion, P., \& Redmond, P. (2017). Social network misuse in the classroom and its impact on male student motivation in UAE tertiary education. IAFOR Journal of Education, 5(SI), 115-131.doi:10.22492/ije.5si.05

Alsharari, N. M. (2018). Internationalization of the higher education system: an interpretive analysis. International Journal of Educational Management, 32(3), 359-381. doi:10.1108/IJEM-04-2017-0082

Gitsaki, C., Robby, M., Priest, T., Hamdan, K., \& Ben-Chabane, Y. (2013). A research agenda for the UAE iPad initiative. Learning and Teaching in Higher Education: Gulf Perspectives, 10(2) doi:10.18538/lthe.v10.n2.162

Hiasat, L. (2018). Blended and experiential learning for Emiratis in tertiary education. Journal of Asia TEFL, 15(3), 874. doi:10.18823/asiatefl.2018.15.3.24.874

Jose, S., \& Chacko, J. (2017). Building a sustainable higher education sector in the UAE. International Journal of Educational Management, 31(6), 752-765. doi:10.1108/IJEM-052016-0102

Kemp, L. J. (2013). Introducing blended learning: An experience of uncertainty for students in the United Arab Emirates. Research in Learning Technology, 21. doi:10.1016/j.lcsi.2015.07.004

Moussa-Inaty, J. (2017). Student experiences of a blended learning environment. International Journal of Learning, Teaching, and Educational Research, 16(9). doi:10.26803/ijlter.16.9.5

Randeree, K. (2008). Managing organizational change: Challenges to the e-learning paradigm in the United Arab Emirates. The International Journal of Learning: Annual Review, 14(10), 41-46. doi:10.18848/1447-9494/CGP/v14i10/45496

Sam, M. K., \& Soong, C. J. (2019). A study of blended learning in higher learning education: Implementation and challenges in 21st Century. INTI Journal, 2019(6). Retrieved from: http://eprints.intimal.edu.my/1279/

Smith, K., \& Hill, J. (2019). Defining the nature of blended learning through its depiction in current research. Higher Education Research \& Development, 38(2), 383-397. doi:10.1080/07294360.2018.1517732

Taha, A. (2007). Networked e-information services to support the e-learning process at UAE University. The Electronic Library, 25(3), 349-362. doi:10.1108/02640470710754850 